\title{
Essential Oil Composition of Thymus $\times$ citriodorus (Pers.) Schreb. at Different Harvest Stages
}

\author{
Ozlem TONCER ${ }^{1 *}$, Sengul KARAMAN ${ }^{2}$, Emel DIRAZ ${ }^{2}$, \\ Tahsin SOGUT ${ }^{1}$, Suleyman KIZIL ${ }^{1}$ \\ ${ }^{1}$ Dicle University, Faculty of Agriculture, Department of Field Crops, Diyarbakir, \\ Turkey; toncer@dicle.edu.tr (*correspondingauthor);tsogut@dicle.edu.tr; suleymankizil@gmail.com \\ ${ }^{2}$ Kahramanmaras Sutcu Imam University, Faculty of Science and Letters, Department of Biology, Kahramanmaras, \\ Turkey; sengulk@ksu.edu.tr; emeldiraz@hotmail.com
}

\begin{abstract}
Thymus is represented by 39 species ( 60 taxa) in Turkey and the rate of its endemism is $45 \%$ in Turkey. The herb is widely used for several purposes. Its essential oil compositions and biologically active substances are affected by the phenological stages. Therefore, the aim of this study is to evaluate the variations in the essential oil composition of Thymus $\times$ citriodorus (Pers.) Schreb. growing in Southeastern Anatolia Region of Turkey at different phenological stages (pre-flowering, full flowering, post flowering). The oils were obtained by hydrodistillation of air-dried samples. The yields of oils (w/w \%) at different phenological stages was respectively $2.0 \%$ at pre-flowering state, $1.9 \%$ at flowering stage, and $1.3 \%$ at post-flowering stage. T. $\times$ citriodorus was determined mainly by using GC/MS. A total of 21 compounds, representing $93.9 \%$ in the preflowering stage, $98.8 \%$ in the flowering stage and $98.91 \%$ in post-flowering of the total oil, were identified. Monoterpene hydrocarbons (terpinolene) and oxygenated monoterpenes ( $\alpha$-terpineol) were observed to have the highest percentage in $T . \times$ citriodorus oil. The major compounds of the oil were terpinolene, $\alpha$-terpineol, linalool, bornyl acetate and borneol. The highest percentage of terpinolene was determined to be $71 \%$ in flowering stages.
\end{abstract}

Keywords: harvest time, GC-MS, lemon thyme, monoterpenes, phenological stage

\section{Introduction}

The genus Thymus L. (Labiatae) consists of approximately 215 species of herbaceous perennials and subshrubs and the Mediterranean region is the gene center of this plant (Nickavar et al., 2005; Agili 2014). Thymus is represented by 39 species (60 taxa) in Turkey, and the rate of its endemism is $45 \%$ (Avci, 2010). Thymus citriodorus (Pers.) Schreb. known as lemon thyme is a hybrid of Thymus vulgaris and Thymus pulegioides (Bagdat et al., 2011). Among Thymus species, lemon thyme (Thymus $\times$ citriodorus) a perennial subshrub medicinal plant, is native to southern Europe and is cultivated in the Mediterranean region. The plant is characterized by a strong fragrance which varies from lemon to orange. The herbage of Thymus species has been widely used for herbal tea, carminative, antiseptic, treating colds, an antioxidant material, and natural substance preservation of foods. Studies have also revealed antibacterial and antifungal properties of the essential oils (Karaman et al., 2001; Sharafzadeh and Bahmani, 2014). Medicinal properties of thyme species come mainly from its essential oil. Primary constituents of lemon thyme essential oil are geraniol, neral, 3-octanone, and borneol (Omidbaigi et al. 2005; Bağdat et al., 2011; Wu et al., 2013).

Many factors determine the content and composition of essential oils in plants such as soil mineral fertilization, light intensity, climatic conditions, growing location, developmental stages, and genetic structure (Farhat et al., 2016). The optimal harvest periods vary depending on climatic conditions of the region where the plant is growing (Ozguven and Tansi, 1998). Plant ontogeny is also one of the most important factors affecting essential oil accumulation in essential oil plants (Sangwan et al., 2001). Omidbaigi et al. (2009) reported that the most suitable time for harvesting of lemon thyme (Thymus $x$ citriodorus) to obtain high essential oil production was at fruit set stage. However, harvesting time should be recommended according to its location and environmental conditions (Badiet al., 2004). The aim of this study was therefore to evaluate the cultivation of Thymus $\times$ citriodorus and to find out variations in essential oil components of this plant due to different developments stages in semi-arid conditions of Southeastern Anatolia Region of Turkey. 
186

\section{Materials and Methods}

\section{Fieldstudies}

The field experiment was conducted at the Department of Field Crops, Faculty of Agriculture, Dicle University, Turkey $\left(37^{\circ} 53^{\prime} \mathrm{N}, 40^{\circ} 16^{\prime} \mathrm{E}, 680 \mathrm{~m}\right.$ above sea level) under the ecological conditions of Diyarbakir in 2011. The soil of the field was sandyloam with $\mathrm{pH} 7.6$, organic matter of $1.2 \%$, phosphorus of $1.62 \%$, and potassium of $8.16 \%$. The climate of the region is dry and hot in summer and long term cold in winters with irregular precipitation. Thymus $\times$ citriodorus seeds were purchased from Garden seeds B.V., Enkhuizen, and Holland. In the third week of January 2011, seeds were sown in a greenhouse conditions. Seedlings were transplanted with $50 \mathrm{~cm}$ row spacing and $30 \mathrm{~cm}$ plant distance in first week of May, 2011 when they reached at $10-15 \mathrm{~cm}$ plant height. Irrigation and cultivation practices were done as needed. The plant was harvested in different developmental stages, viz. pre-flowering, flowering and postflowering stages in the first week of May (plants at the vegetative stage), in the fourth week of May (flowering) and in the second week of June (plants in full blooming) in 2012. The aerial parts were harvested in the morning from 2 year old cultivated plants by randomized collection of 10 individuals for each developmental stage. The plants were cut at a $10 \mathrm{~cm}$ height above soil level and dried in a shaded area. The essential oil of all airdried samples $(20 \mathrm{~g})$ was isolated by hydrodistillation for $3 \mathrm{~h}$, using a Clevenger-type apparatus. Each essential oil was dried over anhydrous sodium kept at $4^{\circ} \mathrm{C}$ until chromatographic analyses.

\section{$G C / M S$ analysis}

GC-MS analyses were realized using Agilent GC-6890II series coupled with Agilent 5975C Mass Spectrometer. The GC was equipped with HP-88 capillary column $(100 \mathrm{~m} \times 250 \mu \mathrm{m} \times$ $0.20 \mu \mathrm{m}$ film thickness) coated with $88 \%$-cyanopropyl arylpolysiloxane. Temperature was set from $70^{\circ} \mathrm{C}$ (1 min) to $230^{\circ} \mathrm{C}$ $\left(20 \mathrm{~min}\right.$ ) at $10^{\circ} \mathrm{C} / \mathrm{min}$. The injection temperature was $250^{\circ} \mathrm{C}$. Injection volume was $1.0 \mu \mathrm{L}$. Carrier gas was He. Injection volume was 1.0 $\mu \mathrm{L}$. Carrier gas: He. Injection mode: split (20:1). MS interface temp: $250^{\circ} \mathrm{C}$; MS mode: EI; detector voltage: 70 $\mathrm{eV}$; mass range: $35-400 \mathrm{~m} / \mathrm{z}$; scan speed (amu/s). The components of the oil were identified by mass spectra with those of pure authentic samples and NIST08, Willey7n.1, and HPCH1607 libraries reference compounds. Retention indices were calculated from gas chromatograms by using logarithmic interpolation between n-alkanes. The homologous series of nalkanes C7-C40, Supelco, USA were used as standard. Retention indices were calculated as HP-88 capillary column (Kizil et al., 2015). All samples were repeated three times for GC/MS analysis. Percentage of each essential oil compound was the mean of three experiments \pm SD.

\section{Results and Discussion}

The essential oil yields (w/w \%) based on the dry weight of the plant, in different harvesting times of developmental growth stages were found as $2.0 \%$ at pre-flowering stage, $1.9 \%$ at flowering stage, and $1.3 \%$ at post-flowering. While the highest oil yield was obtained from pre-flowering stage, while the lowest one was obtained from post-flowering stage (Table 1). The oil yield decreased towards the stage of seed maturity. Similar results reported by Omidbaigi et al. (2009), who studied Thymus $\times$ citriodorus from Iran, indicated that the highest essential oil content was obtained as $2.21 \%$ at beginning of flowering stage. Moreover, the other essential oil content of aerial parts of the plants harvested at full flowering and fruit set stages was 1.45 and $1.66 \%$, respectively. A similar tendency of oil content among phenological stages was also reported by Badi et al. (2004) for Thymus vulgaris. In other studies, Bagdat et al. (2011) reported that the essential oil content of $T$. citriodorus was identified between 1.30 and 1.43\%. Kizil and Toncer (2013) determined that the essential oil content of lemon thyme was $0.9 \%$.

Table 1 shows the essential oil components obtained from three harvest stages of $T$. citriodorus and twenty one compounds identified are listed according to their retention indices were found in the oils (Fig. 1). The majority of these compounds were $93.91 \%$ at the pre-flowering stage, $98.82 \%$ at the flowering stage, and $98.91 \%$ at the post-flowering stage. The essential oil was characterized by a high rate of monoterpene hydrocarbons (61.03-72.39\%), followed by oxygen containing monoterpenes (23.27-33.69\%). Monoterpene hydrocarbons (terpinolene) and oxygenated monoterpenes $(\alpha$-terpineol) were shown to have the highest percentage in Thymus $\times$ citriodorus oil (Table 1$)$.

The major components of Thymus $\times$ citriodorus oils were determined as terpinolene, $\alpha$ - terpineol, linalool, bornyl acetate, and borneol (Table 1). It was determined that main component was terpinolene $(59.0-71.0 \%)$ which appeared to be unstable during the plant growth cycle. The highest content of terpinolene as main component $(71.0 \%)$ was obtained at the flowering stage. The lowest one $(59.0 \%)$ was obtained at the postflowering stage. $\alpha$-terpineol was another main component of the oil. While the highest rate of $\alpha$-terpineol was found as $29.56 \%$ at the post-flowering stage, the lowest rate of $\alpha$-terpineol was determined as $20.03 \%$ at the flowering stage. Linalool content of the oil ranged from $1.35 \%$ to $3.47 \%$. The highest linalool $(3.47 \%)$ was determined in the essential oil of harvested plant at the preflowering stage. Bornyl acetate and borneol content, the other main components, varied between $0.99 \%$ and $1.94 \%$ and between $0.62 \%$ and $1.24 \%$, respectively. Moreover, the highest level of borneol and bornyl acetate was obtained at the post-flowering stage (Table 1). Omidbaigi et al., (2009) determined that geraniol was the major component $(54.2-72.5 \%)$ in Thymus $\times$ citriodorus and obtained the highest geraniol content $(72.5 \%)$ in the essential oil at the pre-flowering stage and the lowest geraniol content $(54.2 \%)$ at the fruit development stage.

Stahl-Biskup and Holthuijzen (1995) reported that geraniol was the main compound (more than 60\%) and also detected geranyl acetate $(1.0 \%)$, geranyl butyrate $(0.8 \%)$, nerol (2.8\%), and citronellol (0.3\%) in Thymus $\times$ citriodorus. Bağdat et al. (2011) also indicated that the main component of essential oil of $T$. citriodorus growing in central Anatolia was 'geraniol'. Wu et al. (2013) found that the main components of T. citriodorus oil were borneol (28.82\%), thymol (14.43\%), 3, 7-dimethyl-1, 6-octadiene-3-ol (8.26\%), 1-methyl-4-[alphahydroxy-isopropyl] cyclohexene $(8.23 \%)$, and terpenes camphor (5.1\%).

In this study, major essential oil component of $T$. citriodorus was determined as terpinolene, which has not been previously reported as main component in $T$. citriodorus essential oil. 
Table 1. Chemical composition of Thymus $\times$ citriodorus (Pers.) Schreb. and essential oil yield (\%) according to different development stages

\begin{tabular}{|c|c|c|c|c|c|c|}
\hline \multirow[b]{2}{*}{ No. } & \multirow[b]{2}{*}{ Components } & \multirow[b]{2}{*}{$\mathrm{RI}^{*}$} & \multirow[b]{2}{*}{$\mathrm{RT}^{* *}$} & \multicolumn{3}{|c|}{ Percentage composition } \\
\hline & & & & Pre-flowering stage & Flowering stage & Post-flowering stage \\
\hline 1 & Sabinene & 1216 & 12.35 & $0.12 \pm 0.12$ & $0.49 \pm 0.63$ & $0.24 \pm 0.00$ \\
\hline 2 & Limonene & 1267 & 12.86 & $0.44 \pm 0.13$ & $0.57 \pm 0.19$ & $0.75 \pm 0.02$ \\
\hline 3 & $\gamma$-Terpinene & 1316 & 13.40 & $0.20 \pm 0.04$ & $0.14 \pm 0.02$ & $0.32 \pm 0.00$ \\
\hline 4 & m-Mentha-1,8-diene, $(+)$ & 1350 & 13.79 & $0.10 \pm 0.00$ & $0.08 \pm 0.00$ & $0.10 \pm 0.00$ \\
\hline 5 & 1.8-Cineole & 1365 & 13.96 & $0.43 \pm 0.01$ & $0.38 \pm 0.00$ & $0.52 \pm 0.01$ \\
\hline 6 & $p$-Cymene & 1399 & 14.37 & $0.11 \pm 0.03$ & $0.11 \pm 0.00$ & $0.62 \pm 0.00$ \\
\hline 7 & 1-Octen-3-ol acetate & 1506 & 15.62 & $0.13 \pm 0.00$ & $0.23 \pm 0.01$ & $0.31 \pm 0.01$ \\
\hline 8 & 1-Octen-3-ol & 1561 & 16.28 & - & $0.15 \pm 0.01$ & $0.08 \pm 0.00$ \\
\hline 9 & $\beta$-Bourbonene & 1613 & 16.91 & $0.08 \pm 0.01$ & $0.21 \pm 0.002$ & $0.08 \pm 0.00$ \\
\hline 10 & Linalool & 1682 & 17.72 & $3.47 \pm 0.01$ & $1.61 \pm 0.02$ & $1.35 \pm 0.03$ \\
\hline 11 & Caryophyllene-E & 1772 & 18.75 & $0.57 \pm 0.02$ & $0.68 \pm 0.03$ & $0.53 \pm 0.01$ \\
\hline 12 & Borneol & 1849 & 19.43 & $1.11 \pm 0.00$ & $0.62 \pm 0.06$ & $1.24 \pm 0.00$ \\
\hline 13 & Terpinolene & 1925 & 20.38 & $61.20 \pm 1.26$ & $71.0 \pm 1.76$ & $59.0 \pm 0.02$ \\
\hline 14 & $\alpha$-Terpineol & 1949 & 20.60 & $22.84 \pm 0.22$ & $20.03 \pm 0.08$ & $29.56 \pm 0.06$ \\
\hline 15 & Bornyl acetate & 1996 & 21.03 & $1.34 \pm 0.00$ & $0.99 \pm 0.09$ & $1.94 \pm 0.00$ \\
\hline 16 & $\alpha$-Terpinyl acetate & 2057 & 21.57 & $0.30 \pm 0.08$ & $0.14 \pm 0.08$ & $0.23 \pm 0.00$ \\
\hline 17 & Trans-Carveol & 2114 & 22.07 & $0.19 \pm 0.01$ & $0.21 \pm 0.04$ & $0.26 \pm 0.00$ \\
\hline 18 & Geraniol & 2157 & 22.42 & - & $0.05 \pm 0.00$ & $0.06 \pm 0.01$ \\
\hline 19 & Thymol & 2544 & 25.62 & - & $0.04 \pm 0.01$ & $0.87 \pm 0.02$ \\
\hline 20 & Caryophyllene oxide & 2561 & 25.76 & $0.73 \pm 0.07$ & $0.42 \pm 0.02$ & $0.58 \pm 0.01$ \\
\hline 21 & Carvacrol & 2618 & 26.26 & $0.55 \pm 0.01$ & $0.67 \pm 0.04$ & $0.27 \pm 0.00$ \\
\hline \multicolumn{7}{|c|}{ Grouped Components } \\
\hline & Monoterpene hydrocarbons & & & 62.17 & 72.39 & 61.03 \\
\hline & $\begin{array}{l}\text { Oxygen-containing } \\
\text { monoterpenes }\end{array}$ & & & 28.27 & 23.27 & 33.69 \\
\hline & Sesquiterpene hydrocarbons & & & 0.65 & 0.89 & 0.61 \\
\hline & Oxygen-containing sesqiterpenes & & & 0.73 & 0.42 & 0.58 \\
\hline & Monoterpene phenols & & & 0.55 & 0.71 & 1.14 \\
\hline & Other & & & 1.54 & 1.14 & 1.86 \\
\hline & Total \% & & & 93.91 & 98.82 & 98.91 \\
\hline & Essential oil yield (\%) & & & 2.0 & 1.9 & 1.3 \\
\hline
\end{tabular}

${ }^{*}$ Retention Index; ${ }^{* *}$ Retention Time

13

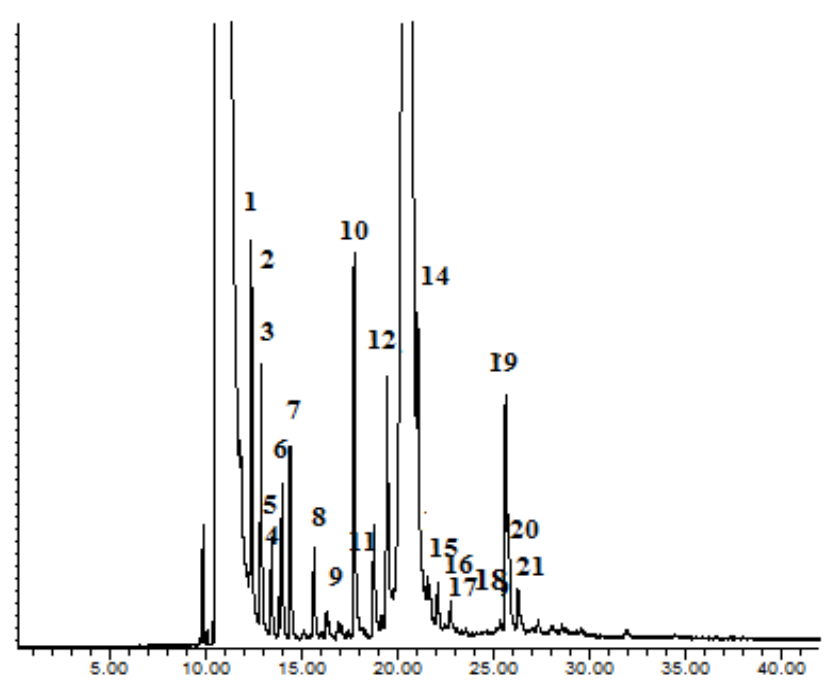

Fig. 1. Typical chromatogram of Thymus citriodorus essential oil components. 1-Sabinene, 2-Limonene, 3- $\gamma$ - Terpinene, 4m-Mentha-1,8-diene, (+), 5-1.8-Cineole, 6-p-Cymene, 7-1Octen-3-ol acetate, 8-1-Octen-3-ol, 9- $\beta$-Bourbonene, 10Linalool, 11-Caryophyllene-E,12-Borneol, 13-Terpinolene, 14- $\alpha$-Terpineol, 15-bornyl acetate, 16- $\alpha$-Terpinyl acetate, 17trans-Carveol, 18-Geraniol, 19-Thymol, 20- Caryophyllene oxide, 21-Carvacrol
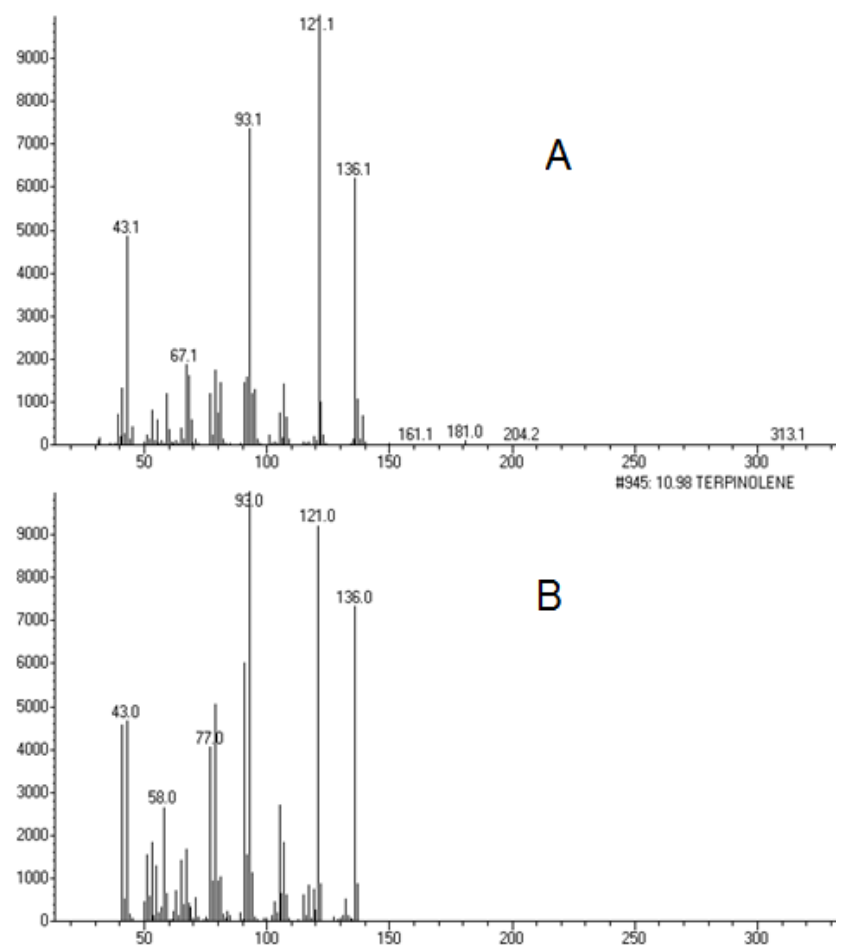

Fig. 2. Comparison of the mass spectrum (A) of obtained from peak 13 in Fig 1, (B) terpinolene spectrum obtained from mass spectral library with the resolved spectra 
GC-MS analysis of which gave rise to four major signal at $\mathrm{m} / \mathrm{z} 121,136,93,43$, also almost the same fragmentations as those of terpinolene were observed (Fig. 2A-B). This was confirmed by comparing GC retention times with pure terpinolene standart. The observed variations in the essential oil content and composition of T. citriodorus might be associated with variations in response to changing weather conditions at different phenological stages and infraspecific chemical variability for the species of the genus Thymus (Corticchiato et al., 1998; Jordan et al., 2006). Loziene et al. (2003) reported both infra-specific and intra-population chemical polymorphisms in Thymus.

Terpinolene is also a constituent of many essential oils e.g. Citrus, Mentha, Juniperus, Myristica species (Civjan, 2012). Choi et al. (2000) reported that terpinolene showed high radical scavengers on DPPH. Although terpinolene, $\alpha$ Terpineol and borneol occur particularly in oils from Pinaceae and in citronella family, and has woody and fruity odor, the other important compound, linalool, is described in literature as floral, citric, fresh and sweet (Elsharif et al., 2015; Surburg and Panten, 2016).

Many chemotypes have been reported for Thymus species. Oh et al. (2008) reported that essential oil components of Thymus species contained commonly monoterpene hydrocarbons ( $\alpha$-pinene, camphene, $\beta$-myrcene, and terpinolene), oxygenated monoterpenes (cis-sabinene hydrate, camphor, borneol, $\alpha$-terpineol, and thymoquinone), a monoterpene phenol (thymol), monoterpene phenol precursors ( $p$-cymene and $\gamma$-terpinene), a monoterpene phenol derivative (thymol methyl ether) and sesquiterpenes ( $\beta$ caryophyllene and $\beta$-bisabolene). The researchers also stated that the grouping of compounds has an important meaning as responsible for the characteristic aroma of Thymus. Asbaghian et al., (2011) reported that the essential oil components of $T$. caucasicus was characterized by 1,8-cineol (21.5\%), thymol (12.6\%), beta-fenchyl alcohol (8.7\%), nerolidol (7.8\%), terpinolene (7.2\%), $\alpha$-pinene (7.0\%), and myrcene (6.8\%). In the oil of T. kotschyanus, carvacrol (24.4\%), $\beta$-caryophyllene (14.5\%), $\gamma$-terpinene (12.4\%), $\alpha$-phellandrene (10.8\%), $p$ cymene $(9.8 \%)$, and thymol $(6.8 \%)$ were the predominant compounds; whereas, the main components of $T$. vulgaris oil were thymol (43.8\%), p-cymene (15.2\%), germacrene-D (11.7\%), terpinolene (3.4\%), carvacrol (3.2\%), $\beta$-caryophyllene (2.8\%), and $\alpha$-thujene (2.2\%). Behravan et al. (2007) reported that thymol (71.07\%), terpinolene (13.08\%), and cymene (10.20\%) were the main component in Thymus vulgaris. Moreover, Dob et al. (2006) identified linalool as main component in Thymus algeriensis oil.

\section{Conclusions}

As a conclusion, it was found that the highest essential oil yield was obtained during the flowering period (2.0\%), and $\alpha$ terpinolene defined as main component, the highest level of it was obtained harvested plants from flowering stage as $71.0 \%$. Harvesting of $T . \times$ citriodorus should be done in flowering plants to achieve better essential oil yield and quality.

\section{References}

Agili FA (2014). Chemical composition, antioxidant and antitumor activity of Thymus vulgaris $L$. essential oil. Middle-East Journal of Scientific Research 21(10):1670-1676.

Asbaghian S, Shafagha, A, Zarea K, Kasimov F, Salimi F (2011). Comparison of volatile constituents, and antioxidant and antibacterial activities of the essential oils of Thymus caucasicus, T. kotschyanus and $T$. vulgaris. Natural Product Communications 6(1):137-140.

Avci AB (2010). A new record and distribution of the endemic Thymu cilicicus Boiss. \& Bal. for the squares B3 and C3 in Turkey. Turkish Journal of Field Crops 15(1):40-42.

Badi,HN, Yazdani D, Mohammad AliS, Nazari F (2004).Effects of spacing and harvesting time on herbage yield and quality/quantity of oil in thyme, Thymusvulgaris L. Industrial Crops and Products 19:231-236.

Bagdat RB, İpek A, Arslan N (2011). Yield and quality parameters of Thymus $\times$ citriodorus (Pers.) Schreb. (synonym T. fragrantisisimus, $T$. serpyllum citratus and T. serpyllum citriodorum) cultivated under Ankara ecological conditions. Planta Medica Proceeding Book 1298 pp, September 49, Antalya, Turkey.

Behravan JA, Ramezani M, Hassanzadeh MK, Ebadi S (2007). Evaluation of Antibacterial Activity of the Essential Oils of Zataria multiflora, Carum copticum and Thymus vulgaris by a Thin Layer Chromatography - Bioautography Method. Journal of Essential Oil BearingPlants 10(3):259-264.

Choi HS, Song HS, Ukeda H, Sawamura M (2000). Radical-scavenging activities of citrus essential oils and their components: detection using 1,1-diphenyl-2-picrylhydrazyl, Journal of Agricultural and Food Chemistry 48(9):4156-61.

Civjan N (2012). Natural products in chemical biology.John Wiley \& Sons, Hoboken, New Jersey.

Corticchiato M, Tomi F, Bernardini AF, Casanova J (1998). Composition and infraspecific variability of essential oil from Thymus herba barona Lois. Biochemical Systematics and Ecology 26:915-932.

Dob T, Dahmane D, Benabdelkader T, Chelghoum C (2006). Studies on the essential oil composition and antimicrobial activity of Thymus algeriensis Boiss. et Reut. International Journal of Aromatherapy 16(2):95-100.

Elsharif AS, Banerjee A, Buettner A (2015). Structure-odor relationships of linalool, linalyl acetate and their corresponding oxygenated derivatives. Frontiers Chemistry 3:57.

Farhat MB, Jordán MJ, Chaouch-Hamada R, Landoulsi A, Sotomayor JA (2016). Phenophase effects on sage (Salvia officinalis L.) yield and composition of essential oil. Journal of Applied Research on Medicinal and Aromatic Plants 3(3):87-93.

Jordan MJ, Martinez RM, Goodner KL, Baldwin EA, Sotomayor JA (2006). Seasonal variation of Thymus hyemalis Lange and Spanish Thymus vulgaris L. essential oils composition. Industrial Crops and Products 24:253-263.

Karaman S, Digrak M, Ravid U, Ilcim A (2001). Antibacterial and antifungal activity of the essential oils of Thymus revolutus Celak from Turkey.Journal of Ethnopharmacology 76:183-186. 
Kizil S, Toncer O (2013). Determination of essential oil and microelement composition Thymus citriodorus and Lippia citriodora. 1st Mediterranean Symposium on Medicinal and Aromatic PlantsMESMAP, Cyprus (Abstract).

Kizil S, Toncer O, Diraz E, Karaman S (2015). Variation of agronomical characteristics and essential oil components of thyme (Thymbra spicata L. var. spicata) populations in semi - arid climatic conditions. Turkish Journal of Field Crops 20(2):242-251.

Loziene K, Vaiciuniene J, Venskutonis PR (2003). Chemical composition of the essential oil of different varieties of thyme (Thymus pulegioides) growing wild in Lithuania. Biochemical Systematics and Ecology 31:249-259.

Nickavar B, Mojab F, Dolat-Abadi R (2005). Analysis of the essential oils of two Thymus species from Iran. Food Chemistry 90:609-611.

Oh SY, Ko JW, Jeong SY, Hong J (2008). Application and exploration of fast gas chromatography-surface acoustic wave sensor to the analysis of Thymus species. Journal of Chromatography A 1205(1-2):117-127.

Omidbaigi R, Sefidkon F, Hejazi M (2005). Essential oil composition of Thymu* ${ }^{*}$ citriodorus L. cultivated in Iran. Flavour and Fragrance Journal 20:237-238.
Omidbaigi R, Fattahi F, Alirezalu A (2009). Essential oil content and constituents of Thymus $\times$ citriodorus $\mathrm{L}$. at different phenological stages. Journal ofEssential Oil Bearing Plants 12(3):333-337.

Ozguven M, Tansi S (1998). Drugyield and essential oil of Thymus vulgaris L. as in influenced by ecological and ontogenetical variation. Turkish Journal of Agriculture andForestry 22:537-542.

Sangwan NS, Farooqi AHA, Shabih F, Sangwan RS (2001). Regulation of essential oil production in plants. Plant Growth Regulation 34:3-21.

Sharafzadeh S, Bahmani A (2014). Main components in aroma profile of genus Thymus: a short review. Journal of Current Research in Science 2(1):158-161.

Stahl-Biskup E, Holthuijzen J (1995). Essential oil and glycosidically bound volatiles of lemonscented thyme. Thymus $\times$ citriodorus (Pers.) Schreb. Flavour and Fragrance Journal 10:225-229.

Surburg H, Panten J (2016). Common fragrance and flavor materials: preparation, properties and uses.John Wiley \& Sons.

Wu S, Wei FX, Li HZ, Liu XG, Zhang JH, Liu JX (2013). Chemical composition of essential oil from Thymus citriodorus and its toxic effect on liver cancer cells. Journal of Chinese Medicinal Materials 36(5):756759. 